\title{
Yellow Fever Virus
}

National Cancer Institute

\section{Source}

National Cancer Institute. Yellow Fever Virus. NCI Thesaurus. Code C97156.

A positive sense single-stranded RNA virus of the flavivirus family that is the causative agent of yellow fever. 